Paidéia, 2005, 15(31), 269-276

\title{
CONCEPÇÃO DE PROMOÇÃO DA SAÚDE DE PSICÓLOGOS NO SERVIÇO PÚBLICO ${ }^{1}$
}

\author{
Cleonice de Faria Barbosa ${ }^{2}$ \\ Universidade de Lavras \\ Iranilde J. Messias Mendes \\ Universidade de Uberaba
}

\begin{abstract}
Resumo: O presente estudo foi realizado com 11 psicólogos da rede municipal de saúde de uma cidade do interior paulista com objetivo de identificar suas concepções sobre a Promoção da Saúde, tendo como suporte teórico os pressupostos da estratégia da Promoção da Saúde. Toma-se como ponto de partida a pesquisa qualitativa, através da entrevista semi-estruturada, com auxílio de um roteiro e uso de gravador. Os dados foram submetidos à Análise Temática de Conteúdo e levaram à proposição de quatro núcleos de sentido: foco do trabalho, rede de trabalho, papel dos psicólogos e Promoção da Saúde-qualidade de vida. Os resultados permitiram considerar que do ponto de vista individual, as atuações dos profissionais buscam uma mobilização no sentido de capacitar o indivíduo para obter melhoria na qualidade de vida e saúde, mas a inexistência de um trabalho integrado, dificulta ações direcionadas para a ampliação das capacidades comunitárias/sociais.
\end{abstract}

Palavras-chave: promoção da saúde; psicologia; psicólogos; saúde pública.

\section{CONCEPTION OF HEALTH PROMOTION OF PSYCHOLOGISTS IN THE PUBLIC UTILITIES}

\begin{abstract}
The study was carried out with 11 psychologists from the municipal health service in a county of São Paulo, in order to identify their conceptions about Health Promotion having the presupposition the health promotion strategy as a theoretical support. We started with a qualitative research through a semi-planned interview using a schedule and a tape recorder. The data were submitted to a content analysis and led to four central senses: focus of work, net of work, psychologists' roles and Health Promotion-life quality. The results made us realize that from an individual stance professionals are searching for a mobilization in order to make the individual able to obtain a better life and health qualities, but as there is no integrated work for extending the social/ community capacities, this improvement becomes more difficult.
\end{abstract}

Key-words: health promotion; psychology; psychologists; public health.

Introdução: O conceito de Promoção da Saúde vem se desenvolvendo desde a década de 70, época em que passou a ser debatido e disseminado em discussões internacionais. Com Leavell e Clarck (1997), ele foi considerado como parte dos níveis de aplicação de medidas preventivas na história natural da doença, incluindo-se no nível de atenção primário.

O Informe de Lalonde (1974) foi o primeiro documento oficial a usar o termo Promoção da Saúde e a colocá-lo no contexto do planejamento estratégico. Este documento chamou atenção para quatro

\footnotetext{
${ }^{1}$ Recebido para publicação em 27/10/2004 e aceito em 10/06/2005.

2 Endereço para correspondência: Cleonice de Faria Barbosa, Rua Joaquim Coelho de Freitas, 1245, Santo Agostinho, Franca - SP, CEP: 14401-360, E-mail: cleobarbosa@netsite.com.br
}

determinantes de saúde, que são: biologia humana, ambiente, estilo de vida e organização da assistência à saúde. Embora este documento não tenha atingido representação política governamental na época em que foi publicado, destacou-se posteriormente, como pilar para o desdobramento da estratégia da Promoção da Saúde. Como exemplo, tem-se a Declaração de Alma-Ata para os Cuidados Primários em Saúde em que a proposta para uma saúde na sua concepção positiva começava a surgir (OMS, 1974). Com a Conferência de Ottawa, no Canadá, em 1986, foi promulgada a Carta de Ottawa dando origem à estratégia da Promoção da Saúde que pode ser compreendida como o processo de capacitação da comunidade para atuar na melhoria de sua qualidade de vida e 


\section{Cleonice de Faria Barbosa}

saúde, incluindo maior participação. Esta Carta define cinco Campos de Ação: Elaboração Implementação de Políticas Públicas Saudáveis; Criação de Ambientes Favoráveis à Saúde; Reforço da Ação Comunitária; Desenvolvimento de Habilidades Pessoais e Reorientação dos Serviços de Saúde (OMS, 1986).

Ocorreram vários movimentos sobre a estratégia da Promoção da Saúde com o intuito de aprimorála. Dentre estes movimentos destacam-se: a Declaração de Adelaide em 1998, a Declaração de Sundsvall em 1991, a Declaração de Santafé de Bogotá em 1992, a Declaração de Jacarta em 1997, a Conferência Ministerial do México em 2000 e Carta de São Paulo que aconteceu em 2002, no Brasil. Todos esses movimentos acabaram por reafirmar os caminhos delineados pela Carta de Ottawa, ainda em 1986.

Assim, Promoção da Saúde nasce como nível de atenção em saúde e renasce como paradigma reestruturante de intervenção. Ela não é uma nova teoria geral sobre saúde, mas é uma estratégia que se apóia em conhecimentos de diversas áreas e em valores como autonomia, responsabilidade, justiça. Ela questiona o modelo biomédico, não para substituí-lo, mas para ultrapassá-lo em seus resultados, superar suas limitações e conter seus malefícios.

A saúde, então, não vem como um objetivo, mas como a fonte de riqueza da vida cotidiana. Trata-se de um conceito positivo que acentua os recursos sociais e pessoais, assim como as aptidões físicas, indo em busca do bem-estar. Esta forma de compreender saúde revelou que a proposta da Promoção da Saúde deve ser um paradigma válido e alternativo aos enormes problemas de saúde e do sistema de saúde dos países. Além disso, esta estratégia obteve notável consenso político em todo o mundo e em diferentes sociedades (MacDonald, 1998).

No Brasil, esta estratégia também influenciou movimentos, como: a VIII Conferência Nacional de Saúde, a Constituição de 1988, a criação do Sistema Único de Saúde, com sua (re) estruturação no momento atual através do Programa de Saúde da Família que tem em suas bases a estratégia da Promoção da Saúde. Nestes movimentos é ressaltada uma proposta de atribuição de liberdade de escolha ao indivíduo, ao mesmo tempo em que o vincula à responsabilidade social. Pois, o projeto de promover saúde na atuação no serviço público deve buscar o desenvol- vimento pleno dos indivíduos como cidadãos autônomos, responsáveis pela sua saúde, autores e inventores da própria vida (Contini, 2001). Ele deve ir além da cura do indivíduo, buscando instrumentalizar a sociedade, individual e coletivamente, no fortalecimento de suas habilidades e potencialidades para o enfrentamento da vida cotidiana (Brasil, 1996).

Bennett e Murphy (1999) lembram que a psicologia tem um papel a desempenhar nos programas dirigidos, quer à mudança individual quer à social ou ambiental, fornecendo teorias orientadas tanto para a promoção e educação para a saúde como para as intervenções de Promoção da Saúde centradas na saúde positiva.

Esta proposição vai ao encontro do que é preconizado pelas Diretrizes Curriculares Nacionais do Curso de Psicologia, que prevê a atuação do psicólogo em diferentes contextos, considerando as necessidades sociais, os direitos humanos, tendo em vista a promoção da qualidade de vida dos indivíduos, grupos, organizações e comunidades. As diretrizes trazem ainda, como parte das competências gerais do profissional, a necessidade de assegurar que a sua prática seja realizada de forma integrada e contínua com as demais instâncias do sistema de saúde, assegurando assim, a importância do trabalho multidisciplinar e intersetorial preconizado pela estratégia da Promoção da Saúde (MEC, 2002).

No entanto, um aspecto comum realçado em trabalhos da área psicológica, como em Silva (1992), Bleger (1992), Campos (1992), Contini (2001), é o de que a Psicologia em sua atuação em saúde voltou-se para atendimentos individuais em consultórios particulares onde os tratamentos são prolongados e de alto custo, numa forma de atuação que se desenvolveu segundo um modelo que minimiza o papel das condições ambientais, principalmente de natureza social, econômica, e cultural. Como agravantes deste quadro, há os modelos curriculares da maioria dos cursos de Psicologia que, influenciados pelo modelo cartesiano, direcionam a formação de seus alunos para um trabalho voltado à clínica individual e esses, ao entrarem em contato com o trabalho em saúde pública, reproduzem o modelo (Contini, 2001).

Bennett e Murphy (1999) evidenciaram que a maioria dos estudos e programas relacionados à Promoção da Saúde preocupa-se com a presença ou 
ausência de fatores de risco da doença ou com a doença propriamente dita. Mesmo quando relacionados com a saúde psicológica, foram consideradas as perturbações psicológicas ou morbidade psiquiátrica, e desconsiderado o bem-estar e a qualidade de vida. Os autores sugerem que os profissionais envolvidos na Promoção de Saúde trabalhem direcionados para encorajar as próprias comunidades a identificarem suas prioridades de saúde e os meios de estas serem alcançadas.

Bleger (1992) alerta que "a função do psicólogo não deve ser basicamente a terapia e sim a saúde pública”(p.20) e como tal precisa ocupar um lugar em toda a equipe de saúde, pois neste contexto existem muitas necessidades, mas também muitas possibilidades de se beneficiar um maior número de pessoas, enquanto que na clínica individualizada este trabalho é mais lento e atende a uma minoria.

Bock (1993) ressalta uma dificuldade do trabalho psicológico que é a fragmentação da ciência psicológica, e explica que a Psicologia apareceu como uma ciência capaz de contribuir para a transformação do indivíduo e da sociedade. No entanto, a inexistência de um projeto coletivo que dê corpo à profissão, "uma profissão da ajuda, da vida, do movimento, da transformação, ou seja, uma profissão com grande potencial, mas que se apresenta pequena e sem projeto na sociedade onde se insere" (p.288), dificulta o desenvolvimento de um trabalho segundo a Promoção da Saúde.

A partir destas reflexões é possível compreender a necessidade de investigação sobre o papel do profissional de Psicologia na Promoção da Saúde como componente favorecedor e estimulador de um repensar da importância da Psicologia na saúde coletiva.

Dito isso, justifica-se este trabalho que tem como objetivo identificar a concepção de Promoção da Saúde de alguns psicólogos que atuam no serviço público com a finalidade de verificar se há uma tendência do profissional de Psicologia em compartilhar responsabilidades na sua atuação visando à emancipação ou se ela se restringe à prevenção específica e tratamento.

\section{Metodologia}

Tendo em vista o propósito deste estudo, op- tou-se por realizar uma pesquisa exploratória descritiva, com um sistema de análise qualitativo. A pesquisa foi desenvolvida na Secretaria Municipal de Saúde de uma cidade do interior paulista, localizada na região Nordeste do Estado. Participaram 11 psicólogos do Serviço Público. Os critérios para seleção foram: o profissional atuar na saúde pública da cidade, aceitar participar do estudo e se dispor a receber os pesquisadores.

A técnica para a coleta de dados, foi a entrevista semi-estruturada, seguindo um roteiro que partiu de interrogações de natureza pessoal, incluindo questões ligadas a pesquisas sobre o tema, já realizadas e disponíveis. O projeto foi aprovado pelo Conselho de Ética da Universidade de origem. A escolha dos participantes foi, inicialmente, aleatória e, posteriormente, determinada pela disponibilidade de horário. No momento da entrevista, foram relidas as informações sobre a pesquisa, ressaltando o caráter sigiloso da identidade, assegurando confidencialidade e apresentado o Termo de Consentimento Livre e Esclarecido, solicitando a assinatura do depoente e autorização para a gravação, com compromisso de serem apagadas após a conclusão do estudo.

Buscou-se construir a análise dos dados através da análise qualitativa que se caracteriza, segundo Biasoli-Alves (1998), "por buscar uma apreensão de significados nas falas, (...) trazendo à tona, na redação, uma sistematização baseada na qualidade, sem a pretensão de atingir o limiar de representatividade" (p.149); procurando sempre apreender e captar os diferentes significados da manifestação natural dos sujeitos, auxiliando a compreensão entre o indivíduo e o seu contexto.

O referencial metodológico utilizado foi o de Análise Temática de Conteúdo, que consiste em descobrir os núcleos de sentido que compõem a comunicação, através de temas ou unidades de significação.

\section{Resultados e discussões}

Os sujeitos participantes deste estudo constituem uma população de adultos jovens, predominando o sexo feminino. Segundo Silva (1992), o rejuvenescimento dos psicólogos e o aumento da participação feminina no setor são tendências dos últimos anos, confirmando as características de idade e do predomínio de mulheres. A maioria dos entrevistados indi- 
cou uma formação direcionada para a Clínica com ênfase em psicanálise. Esse dado mostra que a maioria dos currículos ainda direciona a formação em Psicologia para a clínica, confirmando a literatura, como nos trabalhos de Silva (1992) e Contini (2001).

A partir do material transcrito fez-se o desdobramento de todas as falas em temas ou unidades de significação, visando atingir uma representação do conteúdo e da sua expressão, o que possibilitou a organização do material coletado agrupado em quatro núcleos de sentido: "Foco do Trabalho", "Rede de Trabalho"; "O Papel dos Psicólogos" e "Promoção da Saúde - Qualidade de Vida”.

\section{Foco do trabalho}

O trabalho psicológico nas instituições pesquisadas é voltado para o atendimento de pessoas residentes na cidade, que procuram os cuidados psicológicos por indicação médica ou por escolha espontânea. A população atendida pelos psicólogos inclui crianças, adolescentes, adultos, pais, dependentes químicos e portadores de diabetes. Os atendimentos citados foram: psicoterapia individual, grupal e breve; orientação familiar, triagem; oficinas terapêuticas e atendimentos multidisciplinares. Este dado parece indicar um trabalho diversificado.

Identificou-se como foco do trabalho, a tentativa de fortalecer os indivíduos através do desenvolvimento do autoconhecimento a fim de resgatar suas capacidades; o tratamento psicológico como uma ponte para uma vida mais saudável e o direcionamento do atendimento para a doença, sua detecção, prevenção e tratamento.

\section{Rede de trabalho}

Não é unânime o reconhecimento da presença de rede de trabalho. A interconexão entre o trabalho da Psicologia e das políticas públicas é indicada como inexistente, à medida que, as profissionais desconhecem sua presença e constatam a necessidade de procurar este tipo de relação. Mas na maioria das falas, embora a presença de rede seja considerada, ela é pouco esclarecida o que parece indicar uma sombra e não uma ação planejada ou estruturada. Aparecem, também, os depoimentos de pessoas que buscam o trabalho em rede colocando sua solidariedade, seus deveres de cidadão a serviço do paciente.

\section{Papel dos psicólogos}

Neste terceiro núcleo de sentido é possível observar uma constante preocupação com a pessoa que procura o atendimento psicológico sem perder de vista a especificidade do trabalho; especificidade esta compreendida como alguém que se colcoa disponível para estar com o outro, trabalhando a subjetividade e compreendendo as relações sociais em que a pessoa está inserida.

Tornou-se evidente o compromisso dos psicólogos em aceitar o outro da maneira como ele vem. É mais do que receber ou triar; é ir além. É ouvir, oferecer psicoterapia, rever a história do outro, cuidar, ser bengala, escutar, ficar junto na dificuldade, estar atento, buscar de forma humana o entendimento e resolução de acordo com os limites profissionais e institucionais. No decorrer dos relatos incluídos neste núcleo, é relevante a preocupação dos psicólogos em acolher, ouvir de maneira não crítica, entender; apresentar suas ações direcionadas a apoiar, ser suporte.

Aparece também a importância de indicar rumo, guiar, dirigir para o melhor caminho a seguir e a idéia de orientar, esclarecer sobre doenças, prevenir, educar, conversar, como um processo generalizado de prevenção cuja intenção é informar. A partir de algumas idéias foi possível ver a ausência de percepção da diversidade e das particularidades entre os diferentes sujeitos para se trabalhar a saúde.

É relevante também, o conceito de ser um instrumento na melhoria da saúde facilitando a mudança, clarificando a dificuldade, oferecendo liberdade, favorecendo o conhecimento dos próprios recursos, buscando o crescimento pessoal.

\section{Promoção da Saúde - Qualidade de Vida}

Este núcleo de sentido revela a conceituação de Promoção da Saúde do trabalho psicológico e a sua viabilidade baseada nesta estratégia. Os relatos indicam uma necessidade dos psicólogos de favorecer o desenvolvimento da autonomia, autoconhecimento, auto-estima, sem impor um modelo a ser seguido. As intervenções buscam desenvolver nas pessoas habilidades para viverem a sua verdade de acordo com aquilo que julgam estar correto. Foram consideradas a preservação do senso de realidade das pessoas e sua capacidade de se responsabilizarem por suas ações através da ligação com as regras sociais. 
Também ficou demonstrada a procura pelo desenvolvimento de recursos internos para o lidar com as diferentes situações do dia-a-dia, através do espaço de reflexão, de questionamento sobre o contexto em que a pessoa está inserida, seus relacionamentos, suas angústias, através do desenvolvimento do pensamento, da capacidade crítica e do agir tendo como parâmetro às próprias idéias e não as impostas por alguém ou por alguma ideologia.

A atuação dos psicólogos propiciando espaços para as pessoas se conhecerem é outro aspecto preconizado pela estratégia da Promoção da Saúde e indicado pelos psicólogos deste estudo. Parar, aquietar, respirar, tranqüilizar para então refletir, pensar, atentar para as coisas à nossa volta, envolver-se com o que se está vivendo, seriam atitudes que favorecem o autoconhecimento e conseqüentemente uma decisão, pois permitem que se valorize aquilo que se conhece, se sabe, para então ir em busca do que se quer. Neste espaço criado é favorecido o reconhecimento do próprio ser e, este também, tem a possibilidade de se despir daquilo que não lhe é útil, que não serve mais. Portanto, o trabalho psicológico se relaciona com a coragem para se desfazer do que não serve e se responsabilizar para provocar mudança.

Trata-se de: Atuar para conscientizar o indivíduo retomando conceitos como o desenvolvimento da responsabilidade e direitos da pessoa e da comunidade para com sua própria saúde; trabalhar sentimentos, emoções, direitos, responsabilidades, esclarecer sobre doenças, a importância do tratamento e o elo com a realidade. De acordo com este modelo, instruir a pessoa a buscar inovações e mudar a realidade instituída na procura de melhores condições de vida seria uma forma de promover saúde.

Outro aspecto realçado neste núcleo foi o desenvolvimento de ligações com a vida. Os psicólogos entrevistados parecem compreender bem estas questões quando, ao relatarem o desfecho positivo de algum caso, consideram além da cura da doença, o desenvolvimento de vínculos, de relações afetivas, a redefinição de caminhos. $\mathrm{O}$ interesse volta-se não para uma vida plena, mas para uma modificação na maneira de viver contribuindo para uma experiência mais agradável do que aquela em que o indivíduo se encontrava. Esta busca sugere um princípio básico do trabalho em saúde que é o respeito pelo direito das pessoas de fazerem as suas escolhas.

\section{Considerações finais}

As questões discutidas a partir das falas das participantes confirmam os resultados encontrados na literatura sobre a atuação do psicólogo na Promoção da Saúde, tanto no aspecto mais geral, como também no mais específico. As sínteses feitas contribuem para ampliar discussões sobre necessidades e possibilidades de o psicólogo atuar na saúde pública segundo a estratégia da Promoção da Saúde.

Quanto ao foco de trabalho, apareceram concepções relacionadas à busca de ampliar as chances de vida, e com mais qualidade, tendo a saúde não como um fim, mas como capacidade de autonomia; as que se pode observar com maior freqüência foram as de atuações voltadas para o indivíduo, direcionando o trabalho para a doença e a busca de vida sem doença. Este dado pode ser visto levando em conta pelo contexto em que a maioria dos psicólogos entrevistados está inserida (Ambulatório de Saúde Mental) que, ao receberem para atendimento pessoas em crises pessoais, com dificuldades de relacionamento familiar, social, têm como principal forma de trabalho atuar sobre a doença. Esta constatação encontra-se em acordo com a Organização Mundial de Saúde e a Organização Pan-Americana de Saúde (2001) ao ressaltarem que o ponto de partida mais apropriado para a Promoção da Saúde mental dependerá tanto das necessidades como do contexto social e cultural em que se insere.

Quanto à presença de conexão entre o trabalho da Psicologia e as demais políticas públicas, a maioria dos psicólogos percebe ou vê como necessária a presença de rede de trabalho, embora ainda não desenvolva suas ações neste sentido, nem visualize os caminhos para viabilizar projetos nesta direção. Políticas públicas implicam em setores diferenciados, ações que interligam projetos, favorecem melhor aproveitamento do trabalho realizado. Os dados deste estudo parecem indicar que a Psicologia ainda realiza um trabalho individualizado, se não com as pessoas mas entre os próprios profissionais. Apesar de reconhecida a necessidade de atuação em rede, os profissionais vêem-se engessados diante da realidade; eles demonstram amplos interesses mas poucas possibilidades, confirmando dados da literatura. 


\section{Cleonice de Faria Barbosa}

Quanto ao papel dos psicólogos, foi relevante a preocupação em agir no sentido de ajudar, dar colo, proteger para a pessoa ir se fortalecendo até poder vir a se cuidar mais tarde. Esta informação constata uma concepção de Promoção da Saúde voltada para uma ação de consertar um defeito, a doença, considerando o indivíduo que procura o tratamento como alguém passivo, disponível a ser conduzido, a receber. A orientação no sentido de informar foi outro papel relevante que apareceu nas falas dos psicólogos e, segundo Bezerra Júnior (2001), não atinge um nível de contentamento satisfatório, pois parte da ilusão universalista de que as idéias e sentimentos acerca do que é doença, como se instala, sua causa, e o que as pessoas entendem por cura, tratamento e saúde são universais. Esta constatação evidencia um enfoque maior na prevenção que consiste em atividades dirigidas à transformação dos comportamentos dos indivíduos, com projeção para a família ou grupos, focando nos seus estilos de vida. Contini (2001) considera a forma de atuação voltada para a prevenção específica, conservadora e reducionista, pois se contrapõe aos diversos fatores que integram a saúde da população, individual ou coletivamente. Assim, parece estar ausente o empenho em fazer girar a atuação em torno dos interesses e necessidades individuais e coletivos.

Outros profissionais demonstraram maior direcionamento para a estratégia da Promoção da Saúde, priorizando o desenvolvimento de habilidades pessoais através de questionamentos sobre as relações do indivíduo com o social, da disponibilidade para receber o sujeito do jeito que ele vem e do interesse em facilitar a melhoria de sua saúde na busca da própria verdade. Este dado vai ao encontro das contribuições de Campos (1992) de que é necessário, além de melhorar o serviço de saúde, aliviar a dor e o sofrimento, sendo imprescindível desenvolver, em parceria com o usuário, políticas e práticas que defendam sua vida. O termo empoderamento, conceito central na estratégia da Promoção da Saúde, permeou todos os relatos. Para tanto, é preciso retomar sua definição, como considerada neste estudo. Labonte (s/d) entende o empoderamento como um conceito sistêmico, que reconhece o poder da pessoa desempenhar maior controle sobre a própria vida, inclui a aquisição de uma consciência coletiva da dependên- cia social e da dominação de uma Política Pública que reconheça as situações de exclusão e que favoreça a autonomia do cidadão, no sentido de obter graus crescentes de inclusão na sociedade.

Quanto à Promoção da Saúde - Qualidade de Vida foi notória a preocupação com uma vida mais saudável, direcionando o trabalho para o desenvolvimento das potencialidades e capacidades individuais, seja através da facilitação do crescimento pessoal, da criação de espaços de reflexão, da atuação para a conscientização de responsabilidades e direitos, da redução dos danos; os psicólogos indicaram trabalhar para a saúde na sua concepção ampla e positiva, na busca de autonomia.

Desenvolver habilidades, gerar mudança nos condicionantes sociais através da reflexão, da liberdade de expressão dos aspectos pessoais, daquilo que impede o sujeito de ser ele mesmo, do que emperra uma atitude autêntica e coerente, são passos que estimulam a autonomia. Para Contini (2001), a Promoção da Saúde compõe-se também de ações voltadas para a construção de espaços de reflexões sobre o enfrentamento cotidiano da vida, num processo de conscientização dos fatores que interferem nesse cotidiano. Esta forma de compreender o trabalho psicológico foi enriquecida com as falas que expressam a criação de espaços de reflexão como uma das formas de promover saúde.

Foram evidenciados também, através das falas das entrevistadas, concepções que valorizam a mudança individual como ponto de partida para a Promoção da Saúde e necessidades/possibilidades de uma mudança de modelo na forma de atuar. Bennett e Murphy (1999) acreditam que as intervenções individuais ou em grupo podem reduzir significativamente o risco de doença e são eficazes em função dos resultados, embora tenham um impacto mínimo sobre os níveis populacionais. Contini (2001) salienta, como possibilidade de mudança na atuação dos psicólogos, a socialização do saber produzido, dentro de paradigmas teóricos que apontem para o homem concreto e, ao mesmo tempo, pelo aprender do psicólogo a ter uma atuação interdisciplinar junto a outros interlocutores do fenômeno humano.

Por fim, pode-se apontar que atuar segundo a estratégia da Promoção da Saúde é permitir um permanente e contínuo processo de reflexão sobre a ar- 
ticulação e coerência entre a produção discursiva e a realidade. Isto exige de cada profissional, de cada cidadão, uma postura crítica e positiva para viver e mudar posturas e ações.

\section{Referências Bibliográficas}

Bennett, P. \& Murphy, Y, S. (1999).Psicologia e promoção de saúde. Lisboa: Climepsi.

Bezerra Júnior, B. (2001). Considerações sobre terapêuticas ambulatoriais em saúde mental. Em S.A. Tudis \& N. R. Costa (Orgs.), Cidadania e loucura. (pp.138-150). Petrópolis: Vozes.

Biasoli-Alves, Z. M. M. (1998). A pesquisa em psicologia - análise de métodos e estratégias na construção de um conhecimento que se pretende científico. Em G. Romanelli \& Z. M. M. Biasoli-Alves (Orgs.), Diálogos metodológicos sobre a prática de pesquisa. (pp.135-157), Ribeirão Preto: Legis Summa.

Bleger, J. (1992). Psico-higiene e Psicologia Institucional. Porto Alegre: Artes Médicas.

Bock, A. M. B. (1993). Eu caçador de mim: pensando a profissão de psicólogo. Em M. J. Spink, (Org.), $O$ conhecimento no cotidiano: as representações sociais na perspectiva da psicologia social. (pp.280-291), São Paulo: Brasiliense.

Brasil, Ministério da Saúde. (1996). Promoção da Saúde: Carta de Ottawa, Declaração de Adelaide, Declaração de Sundsvall, Declaração de Bogotá. Brasília, Ministério da saúde.

Buss, P. M.(2003). Uma introdução ao conceito de promoção da saúde. Em D. Czeresnia, (Org.), Promoção da saúde: reflexões, conceitos, tendências. Vol. 1 (pp.15-38) Fiocruz: Rio de Janeiro.

Campos, F. C. B. (1992). Psicologia e saúde: repensando práticas. São Paulo: Hucitec.

Contini, M. L. J. (2001). O psicólogo e a promoção da saúde na educação. São Paulo: Casa do Psicólogo.

Labonte, R. (s/d). Health promotion and empowerment: practice frameworks. Toronto: Centre for Health Promotion. (mimeo).
Lalonde, M. (1974). A New Perspective on the Health of Canadians. Ottawa: Health and Welfare Canadá.

Leavell, H. \& Clark, E. G. (1997). Medicina preventiva. São Paulo: Macgraw.

Macdonald, T. H. (1998). Rethinking health promotion: a global approach. New York: Routledge.

MEC, Ministério da Educação. (2002). Diretrizes curriculares nacionais do curso de graduação em psicologia. Brasil, 2002. Disponível em: <http:// www.mec.gov.br/sesu/f tp / pareceres/ 07202Psicologia.doc>. Acesso em fev. 2004.

OMS. (1974). - Declaração de Alma-Ata. Disponível em: <http://www.dhnet.org.br/direitos/sip/onu/ saúde/almaata.htm>. Acesso em: mar. 2004.

OMS. (1986). Primeira conferência internacional sobre a promoção da saúde. Ottawa, Canadá. (mimeografado)

OMS/OPAS (2001). Relatório mundial da saúde saúde mental: nova concepção, nova esperança. Disponível<http//:www.whqlibdoc.who.int/whr/2001/ WHR_. Acesso em set. 2003.

OPAS (2000). Quinta conferência internacional sobre a promoção da saúde - Declaração do México. Disponível<http:www.opas.org.br/ promocao/upload Acesso em: jan. 2004.

OPAS (2002). Terceira conferência regional Latino-Americana de promoção da saúde e educação para a saúde - Carta de São Paulo. Disponível em: <http://www.opas.org.br/promocao/upload. Acesso em: maio 2004.

Silva, R. C. (1992). A formação em psicologia para o trabalho em saúde pública. Em F.C.B. Campos, (Org.), Psicologia e saúde: repensando práticas, (pp. 25-40). São Paulo: Hucitec. 